\title{
Molecular analysis of the diversity of the sulfide : quinone reductase (sqr) gene in sediment environments

\begin{abstract}
Correspondence
Sung-Keun Rhee

rhees@chungbuk.ac.kr
\end{abstract} \\ Received 18 March 2008 \\ Revised 4 June 2008 \\ Accepted 17 June 2008

\author{
Vinh Hoa Pham, ${ }^{1}$ Jeong-Joong Yong, ${ }^{1}$ Soo-Je Park, ${ }^{1}$ Dae-No Yoon, ${ }^{1}$ \\ Won-Hyong Chung ${ }^{2}$ and Sung-Keun Rhee ${ }^{1}$
}

\author{
${ }^{1}$ Department of Microbiology, Chungbuk National University, 12 Gaeshin-dong, Heungduk-gu, \\ Cheongju 361-763, Korea \\ (KRIBB), Daejeon, Korea
} \\ ${ }^{2}$ National Genome Information Center, Korea Research Institute of Bioscience and Biotechnology

\begin{abstract}
Our newly designed primers were evaluated for the molecular analysis of specific groups of the sqr gene encoding sulfide: quinone reductase (SQR) in sediment environments. Based on the phylogenetic analysis, we classified the sqr sequences into six groups. PCR primers specific for each group were developed. We successfully amplified sqr-like gene sequences related to groups 1, 2 and 4 from diverse sediments including a marine sediment (SW), a tidal flat (TS), a river sediment (RS) and a lake sediment (FW). We recovered a total of 82 unique phylotypes (based on a $95 \%$ amino acid sequence similarity cutoff) from 243 individual sqr-like gene sequences. Phylotype richness varied widely among the groups of sqr-like gene sequences (group 1>group 2>group 4) and sediments (SW $>$ TS $>$ RS $>$ FW). Most of the sqr-like gene sequences were affiliated with the Proteobacteria clade and were distantly related to the reference sqr gene sequences from cultivated strains (less than $\sim 80 \%$ amino acid sequence similarity). Unique sqr-like gene sequences were associated with individual sediment samples in groups 1 and 2. This molecular tool has also enabled us to detect sqr-like genes in a sulfuroxidizing enrichment from marine sediments. Collectively, our results support the presence of previously unrecognized sqr gene-containing micro-organisms that play important roles in the global biogeochemical cycle of sulfur.
\end{abstract}

\section{INTRODUCTION}

Sulfide, the most reduced form of inorganic sulfur, occurs in sediment environments, where it is generated from anaerobic sulfate-reducing bacteria (Detmers et al., 2001; Sorensen et al., 1981). Besides chemical oxidation, microorganisms are involved in the oxidation of sulfide at oxicanoxic interfaces; this reaction initiates the first step of the sulfur oxidation process (Cytryn et al., 2005; Jorgensen, 1982) and produces sulfate or sulfur as the major oxidation product (Friedrich, 1998; Ruepp et al., 2000; She et al., 2001; Theissen et al., 2003).

The oxidation of sulfide to sulfate is mediated by membrane-bound electron-transport systems. Two main

Abbreviations: FW, freshwater lake sediment; RS, river sediment; SOR, sulfide : quinone reductase; SW, marine sediment; TS, tidal flat.

The GenBank/EMBL/DDBJ accession numbers for the partial sqr-like gene sequences determined in this study are EF506241-EF506485; the 16S rRNA gene accession numbers are EF541177-EF541178.

A supplementary figure and table are available with the online version of this paper. enzymic systems participating in the initial step have been intensively studied to understand the mechanism of sulfide oxidation. The electrons from sulfide enter the electrontransport chain either at the level of $c$-type cytochromes, via a sulfide:cytochrome $c$ reductase (FCC) (Kusai \& Yamanaka, 1973a, b, c; Lyric \& Suzuki, 1970a, b, c), or at the level of quinone via a sulfide : quinone reductase (SQR) (Nubel et al., 2000; Schutz et al., 1997, 1998, 1999). FCC was suggested to play an essential role in sulfide oxidation in vivo, and found in a number of chemotrophic and phototrophic sulfide-oxidizing bacteria (Griesbeck et al., 2000; Schutz et al., 1999). However, it is not obligatory in sulfide oxidation since FCC does not occur in a variety of sulfide-oxidizing bacteria, and appears to be dispensable in the micro-organisms in which it is present (Brune, 1995). For example, disruption of the $f c c$ gene in Chromatium vinosum did not have any significant effect on the sulfideoxidizing ability of the cells, showing that the gene was not essential for sulfide oxidation (Reinartz et al., 1998).

The activity of SQR has been investigated in a diverse range of micro-organisms (Theissen et al., 2003). This enzyme 
was first isolated from thylakoids of the cyanobacterium Oscillatoria limnetica (Arieli et al., 1994). Since then, SQR activity has been investigated in a variety of phototrophic and chemotrophic bacteria including Chlorobium limicola (Shahak et al., 1992), Paracoccus denitrificans (Schutz et al., 1998) and Allochromatium vinosum (Reinartz et al., 1998) (for reviews see Griesbeck et al., 2002; Shahak et al., 1999). The sqr gene from the phototrophic bacterium Rhodobacter capsulatus has been isolated, sequenced, and expressed in Escherichia coli (Schutz et al., 1997). Inactivation of the sqr gene causes the loss of phototrophic oxidation and growth capability of $R$. capsulatus with sulfide (Schutz et al., 1999). Nubel's group investigated the sulfide oxidation capability of SQR in membranes of Aquifex aeolicus, one of the most hyperthermophilic and chemolithoautotrophic bacteria, and found that this gene is involved in sulfide-dependent respiration (Nubel et al., 2000). A gene from the genome of Aq. aeolicus VF5 was identified to encode a protein with significant similarity to the SQR of $R$. capsulatus (Deckert et al., 1998). Furthermore, archaeal and mitochondrial oxidation of sulfide is mediated by SQR (Friedrich, 1998; Ruepp et al., 2000; She et al., 2001; Theissen et al., 2003). Diverse symbiotic sulfide-oxidizers have been reported to provide their hosts with carbon and a large array of additional nutrients by using the chemical energy from reduced sulfur (Cottrell \& Cary, 1999; Duperron et al., 2006). Consequently, SQR has been postulated as an enzyme potentially responsible for sulfide oxidation in wide variety of prokaryotes (Dahl et al., 2002). And biological sulfide oxidation is important for the global circulation of sulfur and carbon in various oxic-anoxic interface environments (Griesbeck et al., 2000).

Biological sulfide oxidation occurs in all three domains of life (Griesbeck et al., 2002). Sulfide oxidation has been investigated in various eukaryotes (Furne et al., 2001; Lee et al., 1996; Vande Weghe \& Ow, 1999; Yong \& Searcy, 2001), including even humans (Goubern et al., 2007), which are not specifically adapted to sulfide-rich environments. The activities of SQR and other enzymes allow the organism either to get energy (Oeschger \& Vismann, 1994) or to detoxify sulfide entering the organism from the surrounding environment. This raises the possibility that sulfide oxidation is even more widespread among organisms, and might occur in a wider diversity of habitats; SQR is proposed as an ancient enzyme from the anaerobic world.

Molecular identification based on 16S rRNA genes does not necessarily correspond to metabolic function; therefore PCR techniques for various genes important in biogeochemical cycles have been developed for the functional study of microbial communities (e.g. nirS, nirK, nos $Z$ and nar $G$ for denitrification) (Braker et al., 2000; Kandeler et al., 2006; Scala \& Kerkhof, 1998; Smith et al., 2007). Despite the importance of the sulfide oxidation step in sulfur biogeochemical cycles, development of a molecular tool for studying the diversity of the sqr gene involved in sulfide oxidation has not previously been attempted. In this study, we analysed the phylogeny of $s q r$ gene sequences retrieved from the GenBank database. We designed degenerate PCR primers targeting each group of $s q r$ genes, and studied $s q r$-like gene sequence diversity in various sediment environments.

\section{METHODS}

Phylogenetic analysis of reference sqr sequences. To obtain the known sequences of the sqr gene, a nucleotide search of the GenBank database was performed using the keywords 'sulfide:quinone reductase', and the selected sequences were filtered manually. After a BLAST search using the selected $s q r$ gene sequences, $s q r$ homologues were retrieved again from GenBank. Finally 58 sequences were selected to analyse the phylogeny of $s q r$ as of September 2006.

Sequence alignment was performed using the programs CLUSTAL $\mathrm{W}$ (Thompson et al., 1994) and MAFFT (Nuin et al., 2006). The aligned results exhibited very low similarity to each other in both programs as follows: the mean $q$ score, a sequence similarity scoring function, was 11.75 for CLUSTAL W and 12.48 for MAFFT ( $q$ score is scored from 0 to 100 for each aligned position). For comparison of phylogenetic trees of $16 \mathrm{~S}$ rRNA gene and sqr sequences, the truncated regions of the aligned $s q r$ sequences were eliminated to avoid the regions being treated as gaps. The alignment length including gaps of each group was as follows: group 1, $1372 \mathrm{nt}$ and 447 aa; group 2, $1496 \mathrm{nt}$ and 410 aa; group 3, $869 \mathrm{nt}$ and 409 aa; group 4, $1470 \mathrm{nt}$ and 485 aa; group 5, $1430 \mathrm{nt}$ and 410 aa.

Before performing the phylogenetic analysis for all the sequences, we estimated the best-fit evolution model for those sequences using ProtTest (Abascal et al., 2005), a program which evaluates the sequences for 80 combinations of protein evolution model following the Akaike information criterion (Posada \& Buckley, 2004). The best model for the selected sequences was a WAG model for both alignments (CLUSTAL $\mathrm{W}$ and MAFFT). Due to the low sequence similarity, we selected two methods, maximum-likelihood and Bayesian inference, for phylogenetic analysis. Maximum-likelihood analyses utilized the program Tree-puzzle 5.2 (Schmidt et al., 2002), and the WAG model allowing between-site rate variation was chosen for the protein evolution model. Bayesian analyses using the WAG model were performed with MrBayes 3.1.2 (Ronquist \& Huelsenbeck, 2003). Each inference starting from a random tree and using four Metropolis-coupled Markov Chain Monte Carlo runs (Altekar et al., 2004; Beiko et al., 2006) consisted of 100000 generations with sampling every 100 generations.

Bacterial strains and genomic DNA isolation. The selected reference strains for validation of newly designed primers (listed in the legend of Fig. 2) were obtained from the DSMZ (Braunschweig, Germany; http://www.dsmz.de) as actively growing cultures. The genomic DNA from the reference strains was obtained by applying the Genomic DNA extraction kit (Solgent) according to the manufacturer's instructions. DNA concentration and purity were estimated by spectrophotometry (Nanodrop Technologies), and visual examination after electrophoresis on $0.8 \%(\mathrm{w} / \mathrm{v})$ agarose gels.

Primer design and evaluation using reference strains. Several sets of degenerate PCR primers used to amplify sqr gene fragments were designed based upon each group of sqr gene sequences as classified above. The properties of the most successfully devised primer sets are listed in Table 1. To establish the new primers, 14 reference strains harbouring sqr genes were tested.

One microlitre $(50 \mathrm{ng}$ ) of extracted genomic DNA was used as a template in $20 \mu \mathrm{l}$ amplification reaction mixture. The sqr gene sequence was amplified using an $\mathrm{AB} 2720$ thermal cycler (Applied 
Table 1. Oligonucleotide primers designed and used in this study

\begin{tabular}{|c|c|c|c|c|c|}
\hline Target & Primer name & Sequence $\left(5^{\prime}-3^{\prime}\right)$ & Position $^{*}$ & $\mathbf{F}$ or $\mathbf{R} \dagger$ & $T_{\mathrm{m}}$ \\
\hline \multirow[t]{2}{*}{ Group 1} & SQR-G1-475F & TGY TWY GGC CCG GCB TAY GA & $475-494$ & $\mathrm{~F}$ & 59.8 \\
\hline & SQR-G1-964R & GTS ACC ATS SWT TCR ATC AT & $964-984$ & $\mathrm{R}$ & 52.3 \\
\hline \multirow[t]{2}{*}{ Group 2} & SQR-G2-145F & TGG ACC CTG GTG GGC GSS GG & $145-164$ & $\mathrm{~F}$ & 67.7 \\
\hline & SQR-G2-490R & TTC WKC GGC GCG CCS SCG CA & $490-509$ & $\mathrm{R}$ & 66.7 \\
\hline \multirow[t]{2}{*}{ Group 3} & SQR-G3-199F & TBT AYS AGC CGG GWC TKC TBT & $122-143$ & $\mathrm{~F}$ & 58.5 \\
\hline & SQR-G3-566R & GGY GCM ACS GGG CAT TTG & $471-488$ & $\mathrm{R}$ & 58.9 \\
\hline \multirow[t]{2}{*}{ Group 4} & Ge-140F & TGG ATT CCR TCR AAC ATT TGG GT & $121-143$ & $\mathrm{~F}$ & 62 \\
\hline & Ge-840R & AAT WAG CAT MGC RAA RTC GAA CTC & $823-846$ & $\mathrm{R}$ & 57.4 \\
\hline \multirow[t]{3}{*}{ Group 5} & SQR-G5-437F & TTC AAA GGW GGA AMW ATW RC & $445-464$ & $\mathrm{~F}$ & 51.3 \\
\hline & SQR-G5-799R & TKC CCR GTR TAY GGT GGM A & $809-837$ & $\mathrm{R}$ & 56 \\
\hline & SQR-G5-903R & CAT CRC CYA CWG CRT ARA CGT TAT C & $913-937$ & $\mathrm{R}$ & 60.6 \\
\hline
\end{tabular}

^Position in the sqr gene of Thiobacillus denitrificans ATCC 25259 (NC_007404) from group 1, Staphylococcus aureus (NP_370612) from group 2, Chlorobium tepidum (NP_661917) from group 3, Chlorobium tepidum (AE006470) from group 4, and Sulfolobus solfataricus (NC_002754) from group 5, respectively.

$\dagger \mathrm{F}$, forward; $\mathrm{R}$, reverse.

Biosystems) with EF-Taq DNA polymerase (Solgent). Group $1 s q r$ genes were amplified using the following PCR cycles: 5 min at $94{ }^{\circ} \mathrm{C}$; 2 cycles of $30 \mathrm{~s}$ at $94{ }^{\circ} \mathrm{C}, 30 \mathrm{~s}$ at $45{ }^{\circ} \mathrm{C}, 30 \mathrm{~s}$ at $72{ }^{\circ} \mathrm{C} ; 2$ cycles of $30 \mathrm{~s}$ at $94{ }^{\circ} \mathrm{C}, 30 \mathrm{~s}$ at $50{ }^{\circ} \mathrm{C}, 30 \mathrm{~s}$ at $72{ }^{\circ} \mathrm{C} ; 30$ cycles of $30 \mathrm{~s}$ at $94{ }^{\circ} \mathrm{C}, 30 \mathrm{~s}$ at $52{ }^{\circ} \mathrm{C}, 30 \mathrm{~s}$ at $72{ }^{\circ} \mathrm{C} ; 7 \mathrm{~min}$ at $72{ }^{\circ} \mathrm{C}$; and hold at $10^{\circ} \mathrm{C}$. Group 2 sqr gene sequences were amplified using the following PCR cycles: $5 \mathrm{~min}$ at $94{ }^{\circ} \mathrm{C} ; 30$ cycles of $30 \mathrm{~s}$ at $94{ }^{\circ} \mathrm{C}, 30 \mathrm{~s}$ at $66.5^{\circ} \mathrm{C}, 30 \mathrm{~s}$ at $72{ }^{\circ} \mathrm{C}$; 5 min at $72{ }^{\circ} \mathrm{C}$; and hold at $10{ }^{\circ} \mathrm{C}$. Group 3, group 4 and group 5 sqr gene sequences were amplified using the same PCR cycles as for group 2 but with the elongation step at 58,53 and $51{ }^{\circ} \mathrm{C}$, respectively, instead of $66.5^{\circ} \mathrm{C}$.

Sample collection, DNA extraction and sqr gene amplification. Sediment cores were obtained using a core sampler. Composite sediment samples were prepared by thoroughly mixing surface layer sediments from each site. Marine sediments (SW) were collected with a core sampler from a site in the East Sea, Korea, during July and August 2005. Sampling locations and water depth were as follows: ST3 $\left(128^{\circ} 35^{\prime} \mathrm{E}, 38^{\circ} 20^{\prime} \mathrm{N}, 650 \mathrm{~m}\right)$. The water column above the sediments was oligotrophic, with typical ocean water. Surface samples of tidal flat (TS) were collected from a coastal area at Daecheon, Korea $\left(126^{\circ} 58^{\prime}\right.$ E, $\left.36^{\circ} 53^{\prime} \mathrm{N}\right)$. We collected freshwater sediments (FW) from several metres water depth from the Daechung Reservoir in Korea during the summer bloom season (September 2005). The reservoir is a large branch-type artificial lake created by the construction of a $72 \mathrm{~m}$-high dam in 1980. River sediment samples (RS) were collected from the Musimcheon River $\left(127^{\circ} 28^{\prime}\right.$ E, $36^{\circ} 38^{\prime}$ $\mathrm{N}$ ), which flows through Cheongju city and is highly eutrophic. All samples were collected in sterile plastic tubes using alcohol-sterilized spatulas, and stored at $-80{ }^{\circ} \mathrm{C}$ until analysis.

Total genomic DNA was extracted from $0.5 \mathrm{~g}$ of frozen sample using a Power Soil DNA extraction kit (Mo Bio Laboratories), following the manufacturer's instructions. We determined the total genomic DNA concentration using a spectrophotometer (Nanodrop Technologies). Samples with at least $30 \mathrm{ng}$ DNA $\mu \mathrm{l}^{-1}$ were used for our experiments.

We amplified sqr gene sequences from the sediment DNA by following the optimized PCR conditions. Only amplicons of the expected size were excised from agarose gels to make libraries. Amplification products were purified using a PCR purification kit (Solgent), ligated into the T\&A Cloning Vector kit (Real Biotech Corporation). E. coli $\mathrm{DH} 5 \alpha$ cells were transformed with this ligated vector according to the manufacturer's instructions. Putative positive clones were transferred to a 96-well plate containing Luria broth with ampicillin, grown overnight at $37{ }^{\circ} \mathrm{C}$, and PCR-screened directly for the presence of inserts using the M13 universal primer set. PCR was performed under the following conditions: $5 \mathrm{~min}$ at $94{ }^{\circ} \mathrm{C}$; 30 cycles of $30 \mathrm{~s}$ at $94{ }^{\circ} \mathrm{C}, 30 \mathrm{~s}$ at $55^{\circ} \mathrm{C}, 30 \mathrm{~s}$ at $72{ }^{\circ} \mathrm{C} ; 5 \mathrm{~min}$ at $72{ }^{\circ} \mathrm{C}$; hold at $10{ }^{\circ} \mathrm{C}$. The positive clones from each library were randomly selected, purified using the PCR purification kit (Solgent) and sequenced directly using Bigdye terminator cycle sequencing ready reaction kits (Applied Biosystems).

Phylogeny and diversity analysis of environmental sqr sequences. Multiple alignments of environmental sqr sequences were performed by the same method as used to analyse the reference sqr sequences as described above. Phylogenetic trees were constructed by the maximum-likelihood method, using the program Tree-puzzle 5.2 (Schmidt et al., 2002). Bootstrap analysis (500 replicates) was used to obtain confidence estimates for phylogenetic tree topologies.

Estimations of phylotype coverage, richness, evenness and diversity indices of $s q r$ gene sequences were calculated with ESTIMATES (http:// viceroy.eeb.uconn.edu/EstimateS). The species rarefaction curve of the entire dataset of each group was computed using the individualbased Coleman method with PAST (http://folk.uio.no/ohammer/past). The bias-corrected Chaol estimator of phylotype richness was calculated after 1000 randomizations of sampling without replacement. The percentage of coverage was calculated by Good's method with the formula $[1-(n / N)] \times 100$, where $n$ is the number of phylotypes in a sample represented by one clone (singletons) and $N$ is the total number of sequences in that sample (Good, 1953). Diversity of the sampled sequence set was estimated using the Simpson and Shannon indices within the ESTIMATES application. The Shannon index of evenness was calculated with the formula $E=e^{D} / N$, where $D$ is the Shannon diversity index.

Enrichment of sulfur-oxidizing micro-organisms from marine sediments. Denitrifying enrichment cultures grown on thiosulfate were established with sediment samples of SW. One gram of sediment was inoculated into $100 \mathrm{ml}$ of an anaerobic artificial marine salt medium (Fennell et al., 2004) containing $1 \mathrm{mM}$ of each sulfur compound as the sole electron donor, and $1 \mathrm{mM}$ nitrate as the sole electron acceptor, in a $120 \mathrm{ml}$ serum bottle. After inoculation, the bottle was purged with $\mathrm{N}_{2}$ gas for $30 \mathrm{~min}$ and incubated at $15{ }^{\circ} \mathrm{C}$ in 
the dark. The culture was maintained through successive serial dilutions for 3 months. The turbidity of the culture medium was indicative of thiosulfate oxidation and cell growth. An enrichment culture verified to oxidize tetrathionate, sulfite, sulfide, polysulfide and elemental sulfur in addition to thiosulfate was selected for further molecular analysis. In addition to turbidity, nitrate reduction (Rhee et al., 1997) was used as an indicator of oxidation of sulfur compounds. sqr gene sequences were amplified using PCR conditions developed in this study. In order to analyse the microbial composition of this enrichment culture, we amplified the bacterial 16S rRNA gene sequences using primers $27 \mathrm{~F}$ and 1492R (Weisburg et al., 1991) and constructed a clone library (Park et al., 2006). Sequences of the $16 \mathrm{~S}$ rRNA gene obtained from the clone library were analysed as described previously (Park et al., 2006).

\section{RESULTS AND DISCUSSION}

\section{Phylogenetic analysis of sqr sequences}

Aligned sequences were manually readjusted due to poor sqr sequence conservation in order to allow inter-group sequence comparison. When reference sequences were phylogenetically analysed and compared using the distance matrix, maximum-parsimony and maximum-likelihood methods, we classified the sqr sequences into six distinct groups as shown in Fig. 1. Only one phylogenetic tree, Bayesian inference using MAFFT alignment, is illustrated. The presence of sqr sequences in diverse organisms suggests that sulfide oxidation by SQR is a ubiquitous trait in life that probably evolved from the early anoxic Earth (Theissen et al., 2003).

We identified three of the SQR fingerprints suggested by Griesbeck et al. (2002) - Cys-159, FAD-binding domain III Gly-299 and Cys-353 - in five of the groups, as shown in Supplementary Fig. S1, available with the online version of this paper. Most of the other motifs and residues suggested by Griesbeck et al. (2002) were conserved, and the connecting fragment lengths were invariable. The universally conserved Cys-159 was replaced by Arg in the unclassified group; thus this group was excluded from further analysis. The average inter-group amino acid similarity of SQR sequences was approximately $24 \%$. The average intra-group amino acid sequence similarities of $s q r$ groups $1,2,3,4$, and 5 were approximately $47,39,37,66$, and $61 \%$, respectively.

Phylogenetic trees were calculated from the 16S rRNA genes of identical organism sets harbouring each group of $s q r$ gene sequences. Each $s q r$ group contains specific

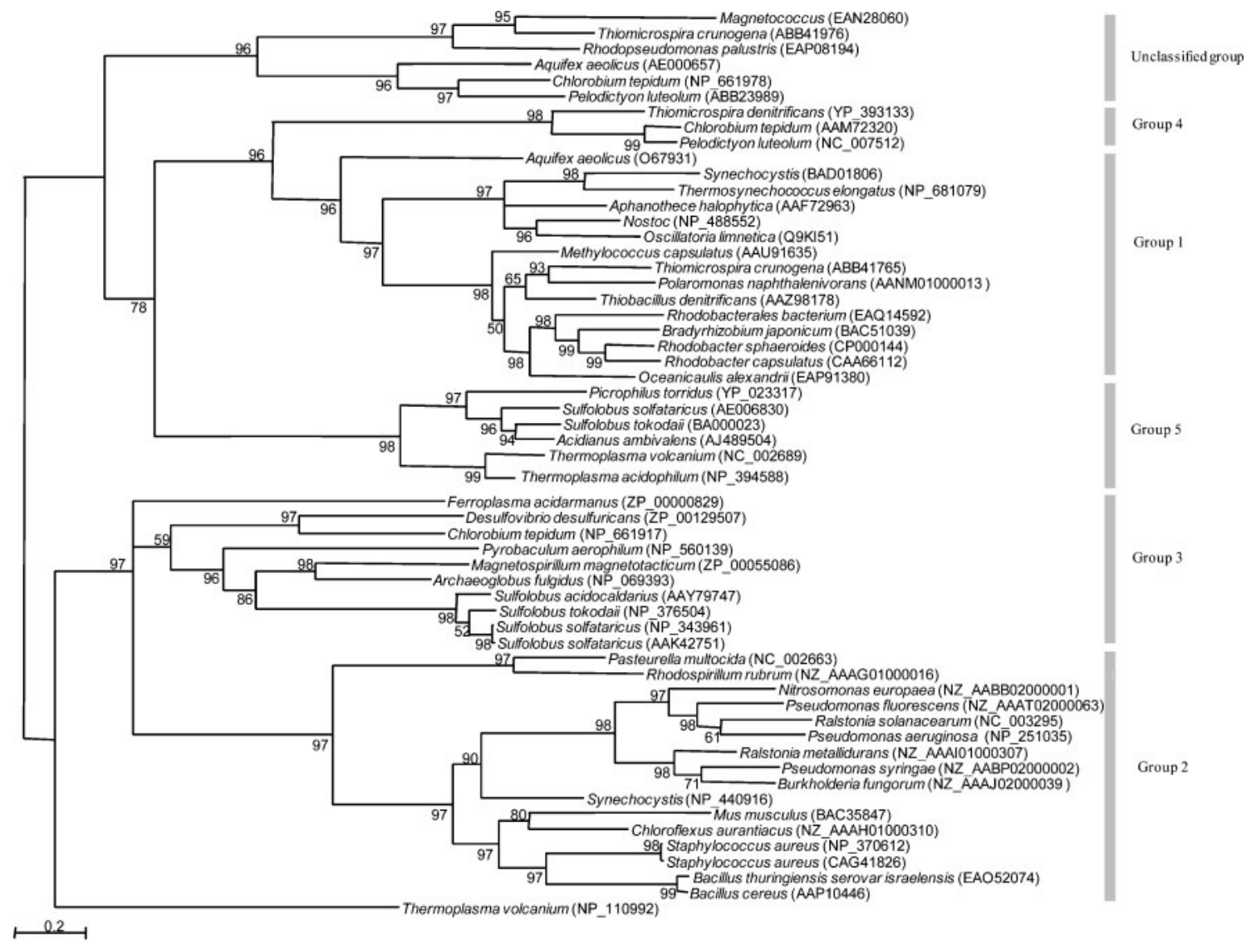

Fig. 1. Phylogenetic analyses of sqr sequences. Sequence groups are indicated to the right of the tree. Bootstrap values $>50$ (expressed as percentages of 100 replications) are shown at branch points. The scale bar indicates 0.2 substitutions per site. 
phylogenetic groups: group 1, Cyanobacteria and Proteobacteria; group 2, Firmicutes and Proteobacteria; group 3, Archaea and others; group 4, e-Proteobacteria and green sulfur bacteria; group 5, Archaea. In groups 1 and 2, which contain the majority of reference $s q r$ sequences, we found a rough correlation in topology of the phylogenetic trees between sqr and 16S rRNA gene sequences. This result indicates that the possibility of promiscuous lateral sqr gene transfer could be excluded.

\section{Design and evaluation of PCR primers for amplification of sqr gene sequences}

Due to the high diversity of $s q r$ gene sequences, we could not find any regions that were sufficiently highly conserved to design universal PCR primers covering all of the $s q r$ groups. Instead, DNA sequences from each sqr group were aligned and used to screen priming sites for PCR amplification. We found several conserved regions for designing primers in each group (Table 1).

For evaluation of the primers designed, we obtained representative reference strains known to harbour genes of each sqr group from the DSMZ microbial collection. Using the genomic DNA as PCR template, PCR amplification conditions for the newly designed primers were tested. sqr gene sequences from reference strains were specifically amplified and yielded PCR products of the expected length (Fig. 2). PCR amplification yielded amplicons of approximately $500 \mathrm{bp}$, $360 \mathrm{bp}, 360 \mathrm{bp}, 720 \mathrm{bp}$, and 390 bp plus $490 \mathrm{bp}$ for groups 1, 2, 3, 4 and 5, respectively. The sequences of PCR amplicons were confirmed by sequencing the band extracted from the gel.

\section{Diversity analysis of environmental sqr sequences}

Diverse sulfide-oxidizing micro-organisms have been isolated from a wide variety of oxic-anoxic interface environments (Brune, 1995). However, the cultivationindependent molecular diversity of sulfide-oxidizing micro-organisms could not be studied. We successfully amplified $s q$-like genes using the primer sets designed for groups 1, 2 and 4 from most of the sediment samples. PCR amplification using primers targeting $s q r$ groups from extremophilic Archaea (groups 3 and 5) failed despite further PCR optimization efforts.

An extensive PCR survey of $s q r$ gene sequences using our primers resulted in the amplification of diverse sqr-like gene sequences both from freshwater and marine sediment environments (Fig. 3). The sqr-like gene sequences retrieved from these environments exhibited an average amino acid sequence similarity of approximately 70, 64, and $75 \%$ in group 1,2, and 4 , respectively. Motifs and spacing between these motifs were conserved in the sqr-like gene sequences recovered from sediments. The phylogenetic trees constructed for each group using the $s q r$-like gene sequences are shown in Fig. 4(a, b, c). Our results suggest that these micro-organisms are diverse and ubiquitous in sediment environments.

We recovered a total of 82 unique phylotypes (group 1, 44; group 2, 29; group 4, 9) based on a $95 \%$ amino acid sequence similarity cut-off from 243 individual sequences. Estimations of species coverage, richness, evenness and diversity indices were calculated for each group, as well as for four subsets of sediment samples (Supplementary Table

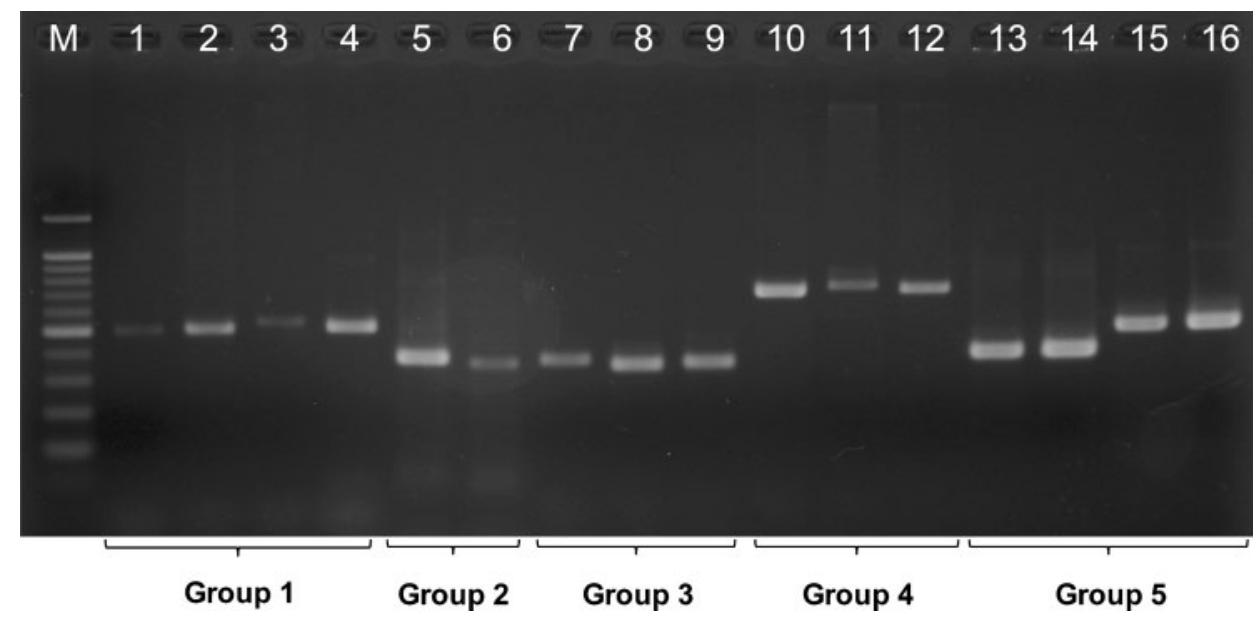

Fig. 2. Agarose gel electrophoresis showing amplification products from pure cultures using the degenerate primers designed in this study. Lane numbers indicate size markers or amplicons from reference strains as follows: $M$, molecular size markers (100 bp ladder); 1, Rhodobacter capsulatus (DSM 155); 2, Thiobacillus denitrificans (DSM 12475); 3, Thiomicrospira crunogena (DSM 12353); 4, Rhodobacter sphaeroides (DSM 158); 5, Cupriavidus metallidurans (DSM 2839); 6, Chloroflexus aurantiacus (DSM 635); 7, Chlorobium tepidum (DSM 12025); 8, Magnetospirillum magnetotacticum (DSM 3856); 9 , Archaeoglobus fulgidus (DSM 4304); 10, Pelodictyon luteolum (DSM 273); 11, Thiomicrospira denitrificans (DSM 1251); 12 , Prosthecochloris aestuarii (DSM 271); 13, 15, Thermoplasma acidophilum (DSM 1728); 14, 16, Sulfolobus solfataricus (DSM 1616). Two reverse primers were tested to amplify sqr gene sequences from the reference strains of group 5 (lanes 13-16). 
Group 1

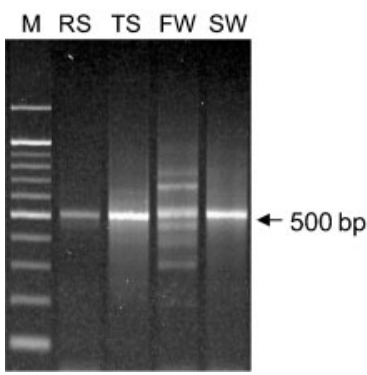

Group 2

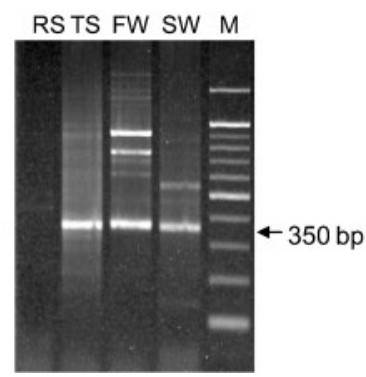

Group 4

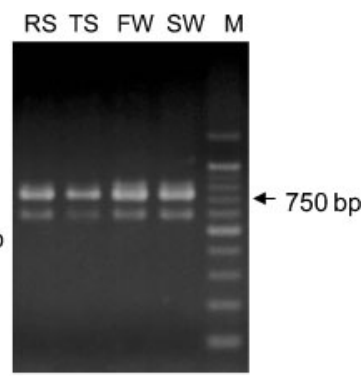

Fig. 3. Agarose gel electrophoresis of $P C R$ products from sediment samples using the degenerate primers designed in this study. The name of the sample is indicated above each lane. M, molecular size markers (100 bp ladder). PCR products of each predicted size are marked by arrows.

S1). Phylotype richness varied widely among sqr groups (group 1>group 2>group 4) and sediment samples (SW $>$ TS $>$ FW $>$ RS). These are likely to be minimal estimates because the rarefaction curve of groups 1 and 2 did not plateau with the current sequencing effort (data not shown). Conventional diversity and evenness indices were also lowest for group 4.

Based on the phylogenetic analysis of PCR clone libraries, we found that individual sediment samples often had unique sqr-like gene sequences associated with them (Fig. 4), i.e. clades of unique sqr-like gene sequences clustered according to habitat. Interestingly, no environmental clone sequence was closely related to those of cultured relatives. This indicates that we have been underestimating the diversity of $s q r$ gene sequences that may be involved in sulfur biogeochemical cycles in sediment environments.

\section{Group 1}

The phylotype richness of group 1 is the highest among our environmental sqr groups. Furthermore, since we detected group 1 sequences in all our marine and freshwater sediments, this group may be abundant and play an important role in sulfide oxidation in oxic-anoxic interface environments; however, this needs to be supported by further investigation. Although the reference $s q r$ gene sequences for group 1 are composed of those from Proteobacteria and Cyanobacteria (see Fig. 1), all of our sqr-like gene sequences were more closely related to those of Proteobacteria than Cyanobacteria. We could not assign our sqr gene sequences to a specific class of Proteobacteria since most of them are distantly related to current GenBank database sequences. The majority $(40 \%)$ of RS clone sequences (representative clones, G1RS16 and G1RS20) were related to $s q r$ gene sequences from a strain of $\beta$ Proteobacteria; these clones exhibited an amino acid sequence similarity with Polaromonas naphthalenivorans of 81 and $74 \%$ respectively. The majority (32\%) of our sqr-like gene sequences (representative clone G1FW4) from the FW environment were related to $s q r$ gene sequences from a strain of $\gamma$-Proteobacteria; this clone exhibited an average amino acid sequence similarity of $83 \%$ with Methylococcus capsulatus. Most of the sequences in this group were habitatspecific since there were only two shared phylotypes among the libraries from different sediments.

\section{Group 2}

Within group 2, we could only amplify diverse sqr-like gene sequences from SW and TS environments. Unique $s q r$-like gene sequences were associated with each habitat since no shared phylotypes were detected between these two sediments. Interestingly, we could detect only one phylotype (with a representative clone, G2FW2) from the freshwater sediments and no PCR amplification could be achieved from the river sediments. Most of the sqr-like gene sequences were related to those of Proteobacteria. Only one clone (G2TS21) was distantly related to the other sequences and was possibly affiliated with Firmicutes. In this group, the closest cultivated relatives still exhibited less than $74 \%$ amino acid sequence similarity to environmental sqr-like gene sequences.

\section{Group 4}

The phylotype richness of group 4 was lower than that seen in other groups. With the exception of FW, most of the sqrlike gene sequences in this group were shared among sediment samples (with three shared phylotypes among nine phylotypes). The closest cultivated relative of most SW, TS and RS clones is Thiomicrospira denitrificans ( $\varepsilon^{-}$ Proteobacteria), although these clones have less than $76 \%$ amino acid sequence similarity with this $\varepsilon$-proteobacterial strain. Recently, $\varepsilon$-proteobacterial sulfide oxidizers were suggested to be important for sulfur biogeochemistry in sulfidic environments (Campbell et al., 2006); however, since only one reference sqr gene sequence was available in this class of Proteobacteria, we could not identify the exact affiliation of our $s q$-like gene sequences. 
(a)
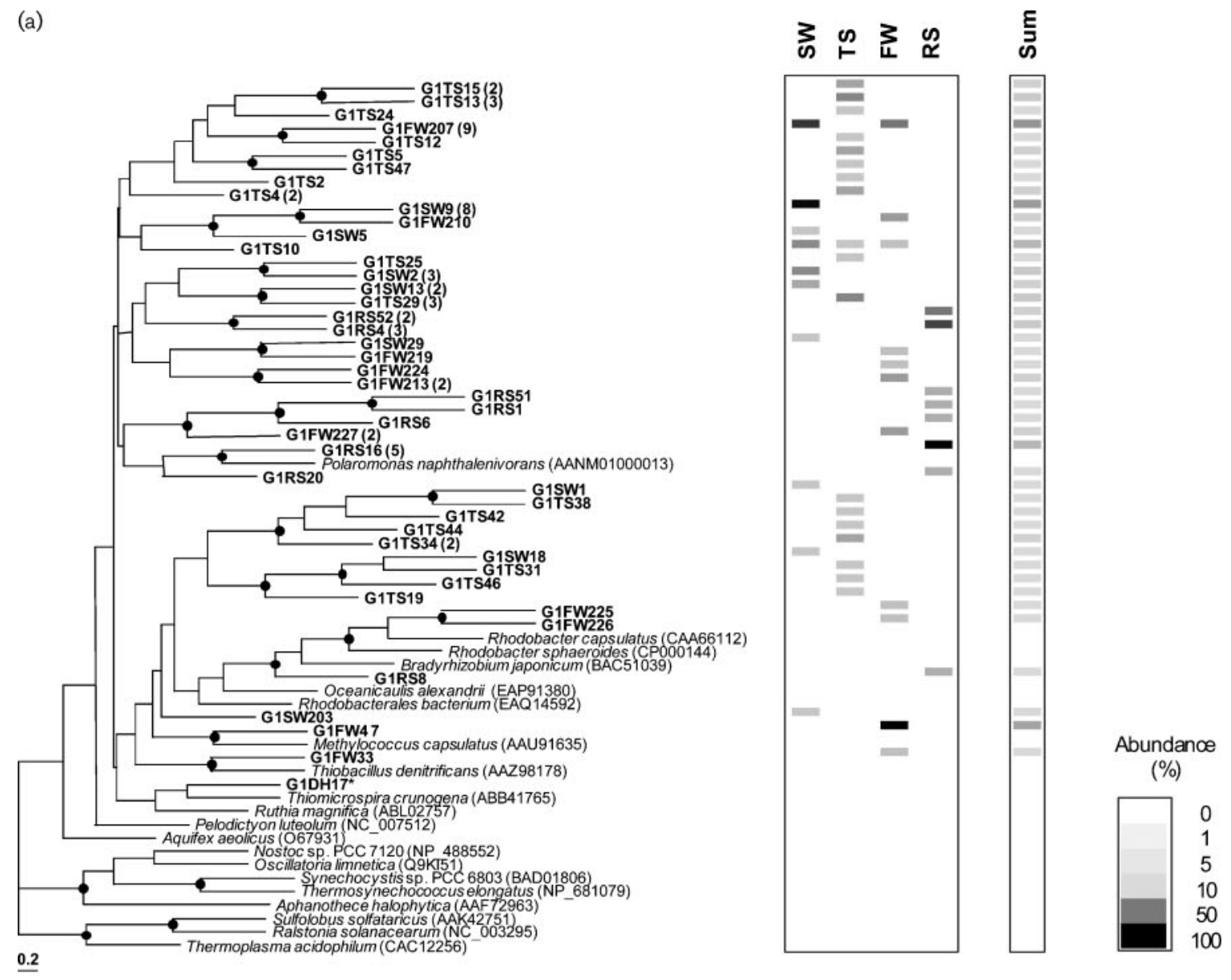

(b)

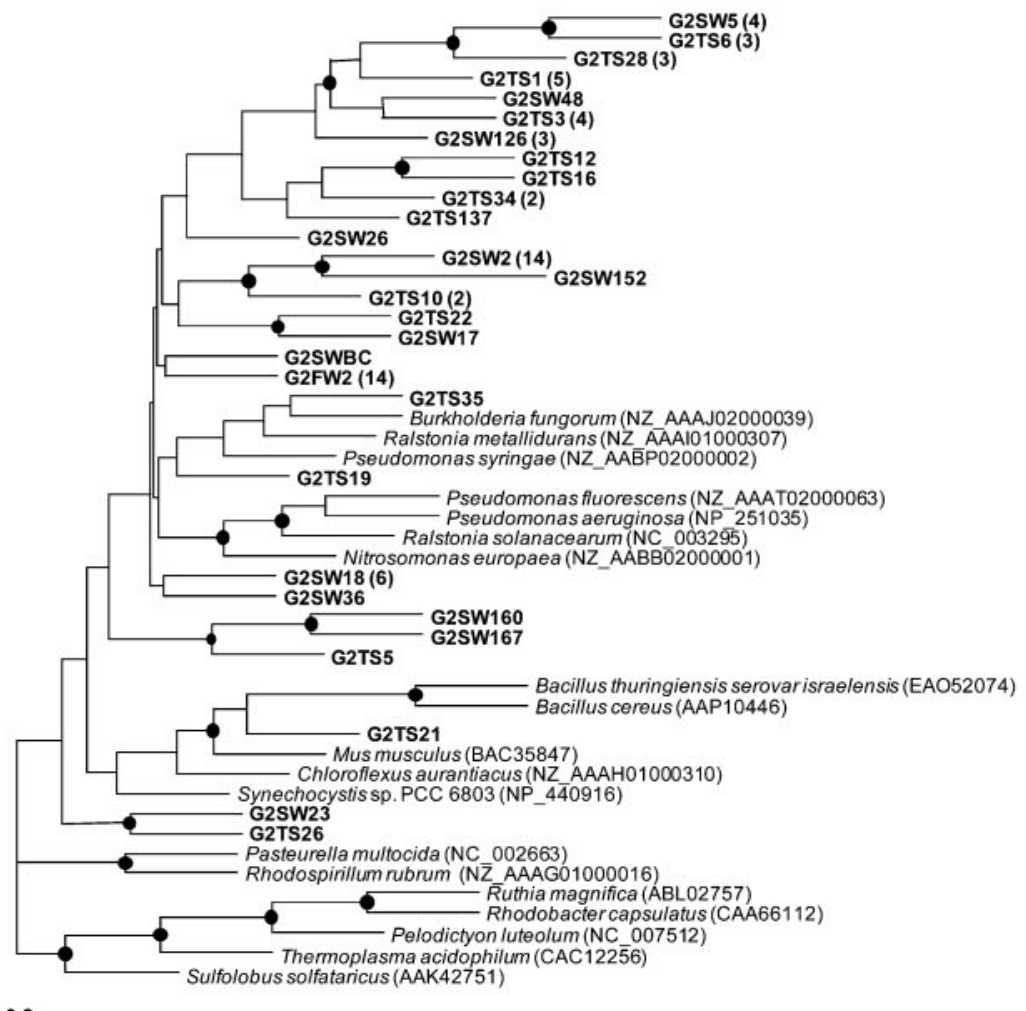


(c)

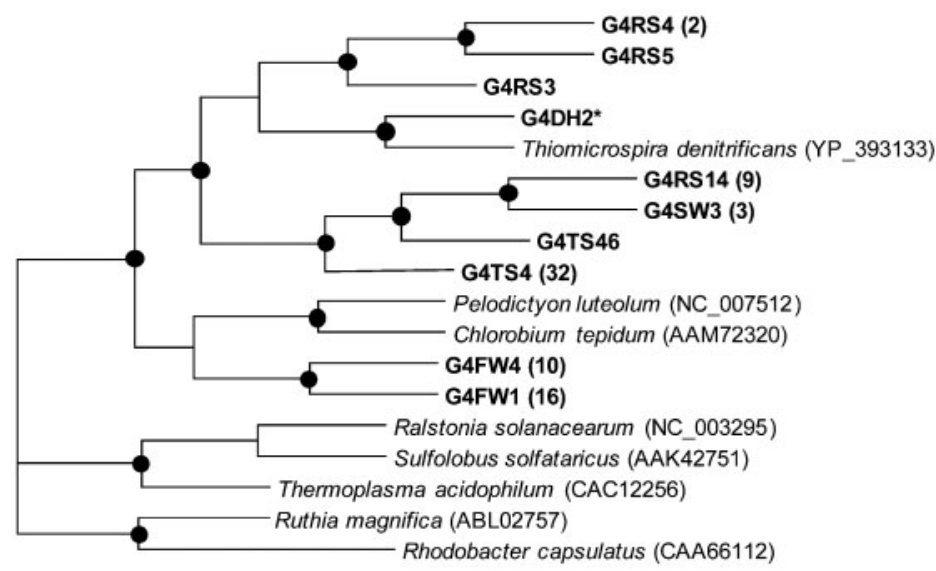

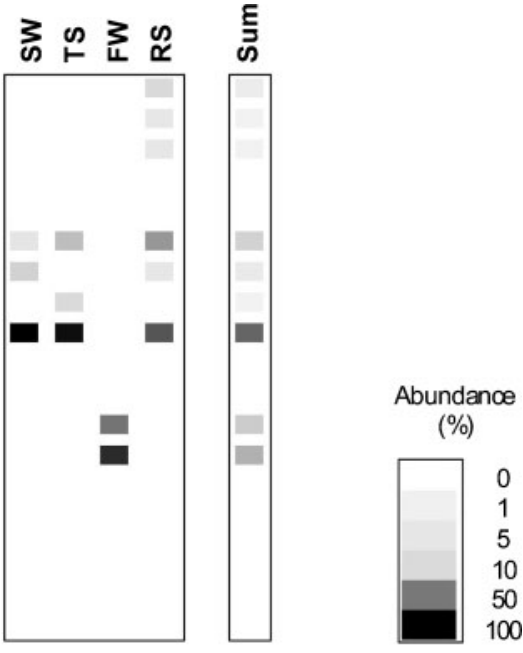

$\underline{0.2}$

Fig. 4. Phylogenetic tree showing the affiliations of sqr gene sequences to selected reference sequences of each group. sqr gene sequences affiliated with group 1 (a), group 2 (b) and group 4 (c) are shown. The tree was calculated by maximumlikelihood analysis. Numbers of clones within each phylotype ( $<95 \%$ sequence similarity as cutoff of phylotype) are shown in parentheses. Significant bootstrap values ( $\geqslant 50 \% ; 500$ replications) are indicated by filled circles at branch points. The scale bar represents $20 \%$ estimated sequence divergence (20 substitutions per 100 amino acids). The right side of the figure shows the relative abundance of phylotypes per samples in grey values (white, $0 \%$ present; black, $100 \%$ of clone library). Letters above the abundance graph correspond to environmental samples. Columns labelled 'Sum' considered all clones in each group. Clones marked with an asterisk (G1DH17 and G4DH2) are from the enrichment culture.

\section{Detection of sqr genes in a sulfur-oxidizing enrichment culture}

A sulfur-oxidizing enrichment culture from marine sediments was characterized using the primers developed in this study. The enrichment was highly purified after being transferred three times using dilution-to-extinction culture methods (see Methods). Only two major 16S rRNA gene sequences were detected in the clone library analysis. These 16S rRNA gene sequences (EF541177 and EF541178) were affiliated with free-living or symbiotic $\gamma$-proteobacterial sulfur oxidizers that were reported by Ravenschlag et al. (1999) (with $84 \%$ 16S rRNA gene sequence similarity to cultured relatives) and Thiomicrospira denitrificans (Brettar et al., 2006) (97\% 16S rRNA gene sequence similarity). We failed to isolate these micro-organisms since they could not develop colonies on any tested solid media.

One phylotype of the sqr-like gene sequences from groups 1 and 4 was amplified (indicated in Fig. $4 \mathrm{a}$ and $\mathrm{c}$ ). The clone, G4DH2, from group 4 is closely related to Thiomicrospira denitrificans (Brettar et al., 2006) (EProteobacteria) with $89 \%$ amino acid sequence similarity. The group 1 clone G1DH17 was distantly related to other environmental clones and cultured relatives, although it is loosely affiliated with those of $\gamma$-Proteobacteria (an endosymbiont, 'Candidatus Ruthia magnifica', and Thiomicrospira crunogena) (Newton et al., 2007; Scott et al., 2006). In cold marine sediments, many clones (18\%) are closely related to symbiotic and free-living $\gamma$-proteobacterial sulfur oxidizers (Ravenschlag et al., 1999). These results indicate that the enriched strain could be one of the sulfide oxidizers playing important roles in sulfur biogeochemical cycles in marine sediment environments. In this study, we could detect and tentatively correlate our novel sqr gene sequences with 16S rRNA gene sequences in the enrichment culture. Our results demonstrated that the molecular tools we have developed might be successfully applied to the characterization of diverse micro-organisms involved in sulfide oxidation.

Although the majority of the sqr-like gene sequences retrieved from various sediments were related to those of diverse Proteobacteria, we could not find any sqr gene sequences closely related to those of cultivated microorganisms. This indicates that the micro-organisms containing these sqr-like gene sequences are previously undiscovered, and diverse micro-organisms involved in sulfide oxidation still remain to be investigated. Further work is necessary to determine the phylogenetic position of these environmental sqr gene sequences.

\section{ACKNOWLEDGEMENTS}

This work was supported by the Korea Research Foundation grant (KRF-2006- 331-C00279) and the Ministry of Science and Technology grant R01-2007-000-20806-0 funded by the Korean Government. 


\section{REFERENCES}

Abascal, F., Zardoya, R. \& Posada, D. (2005). ProtTest: selection of best-fit models of protein evolution. Bioinformatics 21, 2104-2105.

Altekar, G., Dwarkadas, S., Huelsenbeck, J. P. \& Ronquist, F. (2004). Parallel Metropolis coupled Markov chain Monte Carlo for Bayesian phylogenetic inference. Bioinformatics 20, 407-415.

Arieli, B., Shahak, Y., Taglicht, D., Hauska, G. \& Padan, E. (1994). Purification and characterization of sulfide-quinone reductase, a novel enzyme driving anoxygenic photosynthesis in Oscillatoria limnetica. J Biol Chem 269, 5705-5711.

Beiko, R. G., Keith, J. M., Harlow, T. J. \& Ragan, M. A. (2006). Searching for convergence in phylogenetic Markov chain Monte Carlo. Syst Biol 55, 553-565.

Braker, G., Zhou, J., Wu, L., Devol, A. H. \& Tiedje, J. M. (2000). Nitrite reductase genes (nirK and nirS) as functional markers to investigate diversity of denitrifying bacteria in pacific northwest marine sediment communities. Appl Environ Microbiol 66, 2096-2104.

Brettar, I., Labrenz, M., Flavier, S., Botel, J., Kuosa, H., Christen, R. \& Hofle, M. G. (2006). Identification of a Thiomicrospira denitrificanslike epsilonproteobacterium as a catalyst for autotrophic denitrification in the central Baltic Sea. Appl Environ Microbiol 72, 1364-1372.

Brune, D. C. (1995). Sulfur compounds as photosynthetic electron donors. In Anoxygenic Photosynthetic Bacteria, pp. 847-870. Edited by R. E. Blankenship, M. T. Madigan \& C. E. Bauer. Dordrecht: Kluwer.

Campbell, B. J., Engel, A. S., Porter, M. L. \& Takai, K. (2006). The versatile epsilon-proteobacteria: key players in sulphidic habitats. Nat Rev Microbiol 4, 458-468.

Cottrell, M. T. \& Cary, S. C. (1999). Diversity of dissimilatory bisulfite reductase genes of bacteria associated with the deep-sea hydrothermal vent polychaete annelid Alvinella pompejana. Appl Environ Microbiol 65, 1127-1132.

Cytryn, E., van Rijn, J., Schramm, A., Gieseke, A., de Beer, D. \& Minz, D. (2005). Identification of bacteria potentially responsible for oxic and anoxic sulfide oxidation in biofilters of a recirculating mariculture system. Appl Environ Microbiol 71, 6134-6141.

Dahl, C., Prange, A. \& Steudel, R. (2002). Natural Polymeric Sulfur Compounds. Weinheim: Wiley-VCH.

Deckert, G., Warren, P. V., Gaasterland, T., Young, W. G., Lenox, A. L., Graham, D. E., Overbeek, R., Snead, M. A., Keller, M. \& other authors (1998). The complete genome of the hyperthermophilic bacterium Aquifex aeolicus. Nature 392, 353-358.

Detmers, J., Schulte, U., Strauss, H. \& Kuever, J. (2001). Sulfate reduction at a lignite seam: microbial abundance and activity. Microb Ecol 42, 238-247.

Duperron, S., Bergin, C., Zielinski, F., Blazejak, A., Pernthaler, A., McKiness, Z. P., DeChaine, E., Cavanaugh, C. M. \& Dubilier, N. (2006). A dual symbiosis shared by two mussel species, Bathymodiolus azoricus and Bathymodiolus puteoserpentis (Bivalvia: Mytilidae), from hydrothermal vents along the northern Mid-Atlantic Ridge. Environ Microbiol 8, 1441-1447.

Fennell, D. E., Rhee, S. K., Ahn, Y. B., Haggblom, M. M. \& Kerkhof, L. J. (2004). Detection and characterization of a dehalogenating microorganism by terminal restriction fragment length polymorphism fingerprinting of $16 \mathrm{~S}$ rRNA in a sulfidogenic, 2-bromophenol-utilizing enrichment. Appl Environ Microbiol 70, 1169-1175.

Friedrich, C. G. (1998). Physiology and Genetics of Sulfur-Oxidizing Bacteria. London: Academic Press.

Furne, J., Springfield, J., Koenig, T., DeMaster, E. \& Levitt, M. D. (2001). Oxidation of hydrogen sulfide and methanethiol to thiosulfate by rat tissues: a specialized function of the colonic mucosa. Biochem Pharmacol 62, 255-259.

Good, I. J. (1953). The population frequencies of species and the estimation of population parameters. Biometrika 40, 237-264.

Goubern, M., Andriamihaja, M., Nubel, T., Blachier, F. \& Bouillaud, F. (2007). Sulfide, the first inorganic substrate for human cells. FASEB J 21, 1699-1706.

Griesbeck, C., Gunter, H. \& Schutz, M. (2000). Biological Sulfide Oxidation: Sulfide-Quinone Reductase (SQR), the Primary Reaction. Trivandrum, India: Research Signpost.

Griesbeck, C., Schutz, M., Schodl, T., Bathe, S., Nausch, L., Mederer, N., Vielreicher, M. \& Hauska, G. (2002). Mechanism of sulfide-quinone reductase investigated using site-directed mutagenesis and sulfur analysis. Biochemistry 41, 11552-11565.

Jorgensen, B. B. (1982). Ecology of the bacteria of the sulphur cycle with special reference to anoxic-oxic interface environments. Philos Trans R Soc Lond B Biol Sci 298, 543-561.

Kandeler, E., Deiglmayr, K., Tscherko, D., Bru, D. \& Philippot, L. (2006). Abundance of nar G, nirS, nirK, and nosZ genes of denitrifying bacteria during primary successions of a glacier foreland. Appl Environ Microbiol 72, 5957-5962.

Kusai, A. \& Yamanaka, T. (1973a). Cytochrome $c$ (553, Chlorobium thiosulfatophilum) is a sulphide-cytochrome $c$ reductase. FEBS Lett 34, 235-237.

Kusai, A. \& Yamanaka, T. (1973b). A novel function of cytochrome $c$ (555, Chlorobium thiosulfatophilum) in oxidation of thiosulfate. Biochem Biophys Res Commun 51, 107-112.

Kusai, K. \& Yamanaka, T. (1973c). The oxidation mechanisms of thiosulphate and sulphide in Chlorobium thiosulphatophilum: roles of cytochrome c-551 and cytochrome c-553. Biochim Biophys Acta 325, 304-314.

Lee, R. W., Kraus, D. W. \& Doeller, J. E. (1996). Sulfide-stimulation of oxygen consumption rate and cytochrome reduction in gills of the estuarine mussel Geukensia demissa. Biol Bull 191, 421-430.

Lyric, R. M. \& Suzuki, I. (1970a). Enzymes involved in the metabolism of thiosulfate by Thiobacillus thioparus. 3. Properties of thiosulfateoxidizing enzyme and proposed pathway of thiosulfate oxidation. Can J Biochem 48, 355-363.

Lyric, R. M. \& Suzuki, I. (1970b). Enzymes involved in the metabolism of thiosulfate by Thiobacillus thioparus. II. Properties of adenosine-5' phosphosulfate reductase. Can J Biochem 48, 344-354.

Lyric, R. M. \& Suzuki, I. (1970c). Enzymes involved in the metabolism of thiosulfate by Thiobacillus thioparus. I. Survey of enzymes and properties of sulfite : cytochrome $c$ oxidoreductase. Can J Biochem 48, 334-343.

Newton, I. L., Woyke, T., Auchtung, T. A., Dilly, G. F., Dutton, R. J., Fisher, M. C., Fontanez, K. M., Lau, E., Stewart, F. J. \& other authors (2007). The Calyptogena magnifica chemoautotrophic symbiont genome. Science 315, 998-1000.

Nubel, T., Klughammer, C., Huber, R., Hauska, G. \& Schutz, M. (2000). Sulfide: quinone oxidoreductase in membranes of the hyperthermophilic bacterium Aquifex aeolicus (VF5). Arch Microbiol 173, 233-244.

Nuin, P. A., Wang, Z. \& Tillier, E. R. (2006). The accuracy of several multiple sequence alignment programs for proteins. $B M C$ Bioinformatics 7, 471.

Oeschger, R. \& Vismann, B. (1994). Sulphide tolerance in Heteromastus filiformis (Polychaeta): mitochondrial adaptations. Ophelia 40, 147-158.

Park, S. J., Kang, C. H. \& Rhee, S. K. (2006). Characterization of the microbial diversity in a Korean Solar Saltern by 16S rRNA gene analysis. J Microbiol Biotechnol 16, 1640-1645. 
Posada, D. \& Buckley, T. R. (2004). Model selection and model averaging in phylogenetics: advantages of Akaike information criterion and Bayesian approaches over likelihood ratio tests. Syst Biol 53, 793-808.

Ravenschlag, K., Sahm, K., Pernthaler, J. \& Amann, R. (1999). High bacterial diversity in permanently cold marine sediments. Appl Environ Microbiol 65, 3982-3989.

Reinartz, M., Tschape, T., Bruser, T., Truper, H. G. \& Dahl, C. (1998). Sulfide oxidation in the phototrophic bacterium Chromatium vinosum. Arch Microbiol 170, 59-68.

Rhee, S. K., Lee, G. M., Yoon, J. H., Park, Y. H., Bae, H. S. \& Lee, S. T. (1997). Anaerobic and aerobic degradation of pyridine by a newly isolated denitrifying bacterium. Appl Environ Microbiol 63, 2578-2585.

Ronquist, F. \& Huelsenbeck, J. P. (2003). MrBayes 3: Bayesian phylogenetic inference under mixed models. Bioinformatics 19, 1572-1574.

Ruepp, A., Graml, W., Santos-Martinez, M. L., Koretke, K. K., Volker, C., Mewes, H. W., Frishman, D., Stocker, S., Lupas, A. N. \& Baumeister, W. (2000). The genome sequence of the thermoacidophilic scavenger Thermoplasma acidophilum. Nature 407, 508-513.

Scala, D. J. \& Kerkhof, L. J. (1998). Nitrous oxide reductase (nosZ) gene-specific PCR primers for detection of denitrifiers and three nos Z genes from marine sediments. FEMS Microbiol Lett 162, 61-68.

Schmidt, H. A., Strimmer, K., Vingron, M. \& von Haeseler, A. (2002). TREE-PUZZLE: maximum likelihood phylogenetic analysis using quartets and parallel computing. Bioinformatics 18, 502-504.

Schutz, M., Shahak, Y., Padan, E. \& Hauska, G. (1997). Sulfidequinone reductase from Rhodobacter capsulatus. Purification, cloning, and expression. J Biol Chem 272, 9890-9894.

Schutz, M., Klughammer, C., Griesbeck, C., Quentmeier, A., Friedrich, C. G. \& Hauska, G. (1998). Sulfide-quinone reductase activity in membranes of the chemotrophic bacterium Paracoccus denitrificans GB17. Arch Microbiol 170, 353-360.

Schutz, M., Maldener, I., Griesbeck, C. \& Hauska, G. (1999). Sulfidequinone reductase from Rhodobacter capsulatus: requirement for growth, periplasmic localization, and extension of gene sequence analysis. J Bacteriol 181, 6516-6523.

Scott, K. M., Sievert, S. M., Abril, F. N., Ball, L. A., Barrett, C. J., Blake, R. A., Boller, A. J., Chain, P. S., Clark, J. A. \& other authors (2006).
The genome of deep-sea vent chemolithoautotroph Thiomicrospira crunogena XCL-2. PLoS Biol 4, e383.

Shahak, Y., Arieli, B., Padan, E. \& Hauska, G. (1992). Sulfide quinone reductase (SQR) activity in Chlorobium. FEBS Lett 299, 127-130.

Shahak, Y., Schuetz, M., Bronstein, M., Hauska, G. \& Padan, E. (1999). Sulfide-dependent anoxygenic photosynthesis in prokaryotes: sulfide-quinone reductase (SQR). In The Phototrophic Prokaryotes, pp. 217-228. Edited by G. A. Peschek, W. Loeffelhardt \& G. Schmetterer. New York: Plenum.

She, Q., Singh, R. K., Confalonieri, F., Zivanovic, Y, Allard, G., Awayez, M. J., Chan-Weiher, C. C., Clausen, I. G., Curtis, B. A. \& other authors (2001). The complete genome of the crenarchaeon Sulfolobus solfataricus P2. Proc Natl Acad Sci U S A 98, 7835-7840.

Smith, C. J., Nedwell, D. B., Dong, L. F. \& Osborn, A. M. (2007). Diversity and abundance of nitrate reductase (narG and napA), and nitrite reductase (nirS and nrfA) genes and transcripts in estuarine sediments. Appl Environ Microbiol 73, 3612-3622.

Sorensen, J., Christensen, D. \& Jorgensen, B. B. (1981). Volatile fatty acids and hydrogen as substrates for sulfate-reducing bacteria in anaerobic marine sediment. Appl Environ Microbiol 42, 5-11.

Theissen, U., Hoffmeister, M., Grieshaber, M. \& Martin, W. (2003). Single eubacterial origin of eukaryotic sulfide:quinone oxidoreductase, a mitochondrial enzyme conserved from the early evolution of eukaryotes during anoxic and sulfidic times. Mol Biol Evol 20, 1564-1574.

Thompson, J. D., Higgins, D. G. \& Gibson, T. J. (1994). CLUSTAL W: improving the sensitivity of progressive multiple sequence alignment through sequence weighting, position-specific gap penalties and weight matrix choice. Nucleic Acids Res 22, 4673-4680.

Vande Weghe, J. G. \& Ow, W. D. (1999). A fission yeast gene for mitochondrial sulfide oxidation. J Biol Chem 274, 13250-13257.

Weisburg, W. G., Barns, S. M., Pelletier, D. A. \& Lane, D. J. (1991). 16 S ribosomal DNA amplification for phylogenetic study. J Bacteriol 173, 697-703.

Yong, R. \& Searcy, D. G. (2001). Sulfide oxidation coupled to ATP synthesis in chicken liver mitochondria. Comp Biochem Physiol B Biochem Mol Biol 129, 129-137.

Edited by: G. Muyzer 